\title{
A Family Affair: Caring in Teaching and Implications for Teacher and Researcher Preparation
}

\author{
James A. Bernauer \\ Robert Morris University \\ Mary Pat Bernauer \\ McCarthy Training and Consulting \\ Patrick J. Bernauer \\ University of Dayton
}

\begin{abstract}
The purpose of this study was to explore how perceptions of remembered instances of teacher caring in K-College impacted the motivation of a college student. Implications for teacher preparation programs and educational research were then drawn from these perceptions. The first part of the title "A Family Affair" stems from the fact that the authors are members of the same family - Father, Mother, and Son. Both the father and mother had prior knowledge of some (not all) of the instances of caring and non-caring described by their son and thus shared a privileged insider position that offered unique insights while cooperative peer checking was used both during and after the interview to help promote the trustworthiness of findings. It was found that the degree of caring shown by teachers had a profound influence on the participant's willingness to put forth effort especially in those courses that were not his favorite subjects which suggests that a strong connection exists between caring and student motivation. An important implication of this study is that teachers and those responsible for teacher preparation programs would benefit by being aware of the impact of caring on students' engagement and attitude toward learning. If the ultimate purpose of educational research is to contribute to effective teaching, then the "soft variable" of caring should be considered an important component of researcher preparation. It is hoped that readers will find this study to be transferable to the degree that it resonates with their own experience as teachers, students, and parents, and which we refer to as "experiential validity".
\end{abstract}

Keywords: Caring, experiential validity, oral coding, perceptual realities, qualitative tradition, quantitative tradition

James A. Bernauer is a Professor of Education at Robert Morris University in Pittsburgh, PA. (USA) where he teaches educational psychology, qualitative methodology, and quantitative methodology.

Bernauer@rmu.edu

Mary Pat Bernauer is the owner of McCarthy Training and Consulting in Pittsburgh, PA where she trains individuals and corporations on Microsoft and other specialty software.

mpmccarthy@pobox.com

Patrick J. Bernauer is a senior at the University of Dayton in Dayton, $\mathrm{OH}$ where he is majoring in Digital Media and journalism.

Bernauerp1@udayton.edu

Brock Education Journal, 26(2), 2017 
"I wish I could care what you do or where you go but I can't... My dear, I don't give a damn." (Gone With The Wind, 1939)

"For I don't care too much for money, for money can't buy me love" (Can't Buy Me Love, The Beatles, 1964)

"The longer we consider and examine the present day methods of education, the more clearly we recognise that children lack the care and consideration which would be in accord with their present and future needs, a care which considers equally the child's mental and physical needs and capacities. We notice that if children are not given the care which takes their stage of human development into consideration, they will lack the foundation for the task ahead in school and for their later lives in general." (Friedrich Froebel, Founder of Kindergarten, 17821852; Moore, 1991)

“They don't care what we know until they know that we care." (Madeline Hunter, 1982)

The above array of quotes (where care and caring have been emphasized) convey some of the meanings and nuances that can be used to define these terms. In this article, the concept of caring in education was investigated from the perspective of a SonResearcher (SR) and further elucidated by the Mother-Researcher (MR). SR was the primary focus in this study since he was asked by the Father-Researcher (FR) to share his experiences and perspectives related to remembered instances of caring and non-caring during his elementary, high school, and college years during a group interview.

The following Research Questions guided data collection:

$R Q 1$. What instances of caring and non-caring does $S R$ readily recall from elementary and high school and to what extent are these recalled instances perceived by $S R$ as having a continuing impact on motivation to do well in college?

$R Q 2$. What instances of caring and non-caring does $S R$ readily recall from college during his Freshman and Sophomore years and to what extent are these recalled instances perceived by $S$ as having a continuing impact on his motivation to do well in college?

RQ3. Based on recalled instances of caring and non-caring in elementary school, high school, and college, what suggestions would SR make to help teachers and professors make a stronger impact on their students in terms of their motivation to do well in school and to pursue their career aspirations?

RQ4: What perspectives are offered by $M R$ in relation to $R Q 1$ to $R Q 3$ ?

FR envisioned these questions as a fertile field for transforming data via "description, analysis, and interpretation" (Wolcott, 1994) including both tacit and propositional knowledge (Polanyi, 1962) in order to understand the role of caring in relation to 
teaching, learning, and research. It was anticipated that themes would emerge from intrafamily dialogue where the interactions among MR, SR, and FR were seen as positive contributions toward understanding the influence of caring on learning and motivation rather than as a source of "bias". FR used dialogue coupled with empathetic understanding and reflection as a type of "member checking" to promote the trustworthiness of data and to integrate tacit knowledge including emotion, intuition, and body language with propositional knowledge that was conveyed via straight-forward language captured in the oral responses. The ultimate aim was to get to the heart of the matter regarding the impact of caring on students and therefore its potential role in both teacher and researcher preparation programs.

\section{The Qualitative and Quantitative Traditions}

Is it not sometimes the case that we qualitative researchers believe that our quantitatively-oriented colleagues do not care as much as we do about participants and that these colleagues think that qualitative research is inferior to quantitative research? One older and one more recent source may weaken this belief. Bauswell (1994) introduces his book Conducting Meaningful Experiments: 40 Steps to Becoming a Scientist by first saying that "meaningfulness" can be defined in different ways by different people but that "I happen to define a meaningful research study as one that has the potential of actually helping people and improving the human condition" (p. 1). Pilcher and Cortazzi (2016) interviewed 17 researchers who leaned quantitatively and found that most of them not only did not deprecate qualitative approaches but found these approaches to be valuable to scientific inquiry. So, even if we differ with our quantitatively-oriented colleagues in terms of epistemology and methods, it might be beneficial to remind ourselves once in awhile that we are all on the same team and we hope that this article is received in this same spirit!

\section{Purpose of Education}

Purpose is behind everything that we do. In the case of education, aspiring teachers are typically required to arrive at their own "philosophy of education" that captures their values and beliefs. Here is our suggested statement of educational purpose --

The purpose of education is help students grow artistically, cognitively, emotionally, morally, and socially within a safe, encouraging, and caring environment, leave as lifetime adventurers who are ever ready to question and learn about themselves, others, and their world, and to meaningfully contribute to the interrelated welfare of self, others, and world throughout their lives.

Purpose is described here in terms of growth and caring in relation to five inborn capacities and provided a context for both data collection and data analysis in this study. We additionally suggest that this purpose statement can provide a sound basis for developing and improving teacher and researcher preparation programs.

\section{Framework and Methods}

A group interview was conducted on August 4, 2016 and FR tried to keep the stated 
educational purpose firmly in mind during this interview. Based on the process of Oral Coding (2015a), both analysis and interpretation were refined in the weeks that followed. Oral Coding was used to analyze interview data because it relies on an aural-oral approach for making sense of data. FR introduced the process of Oral Coding in a study that focused on higher education (Bernauer, Semich, Klentzin, \& Holdan, 2013) where one of his co-authors used phenomenological coding while FR used Oral Coding to analyze data that were collected during focus group sessions. It was found that there was substantial agreement across findings and interpretations. FR then used Oral Coding in a study that explored the remembrances of graduates of Catholic schools over several decades and found that Oral Coding helped to preserve the unique voices of participants as he went about transforming raw data into written text (Bernauer, 2015b). Finally, FR attempted to codify Oral Coding more explicitly into seven steps (Bernauer, 2015a).

While analyzing data for this current study, FR found that, while he adhered to the spirit of the seven steps, that he drifted from them especially in the way that the three technologies of GarageBand on the Mac laptop that was used to initially record the interview, QuickVoice Pro on the IPhone that served as the secondary recording device, and Dragon Dictate on the Mac that was used to transcribe from voice to text in Microsoft Word overlapped and intersected. Consequently, it would be difficult to describe the exact sequence of using these technologies because FR found himself "jumping around" among them and would be hard-pressed to try and present a linear account of a very non-linear process. Nonetheless, FR intends to continue experimenting with this method of transforming data that will hopefully serve to generate useful information to those who are interested in using this method in their own work.

In addition to the foundational role of educational purpose, Cooper and Garner (2012) stress that the sequence of Relationships-Relevance-Rigor is critical since developing relationships with students lays the necessary prerequisite for the other two components of effective teaching. In addition both Noddings (2005) and Heshusius (1996) provide persuasive arguments for positioning caring into any discussion of teaching and learning. FR also tried to follow Wolcott's (1994) suggestion to transform qualitative data into a written account through description - analysis - interpretation while recognizing that in the actual practice of making sense of data, that these processes often overlap. FR also tried to incorporate the ideas related to critical thinking in qualitative data analysis (Bernauer, Lichtman, Jacobs, \& Robertson, 2013). These sources offer a framework for making sense of qualitative data and it was within this framework that FR utilized "Oral Coding" to analyze and interpret data in relation to the question of caring in education using a multi-phase process using voice recordings to transform data into a written account rather than using verbatim transcriptions of oral data. Finally, while there was only one primary informant (SR) and two secondary informants (MR and FR), it is hoped that readers will identify their own points of connection based on their personal experiences as teachers, students, and/or parents. We refer to these connections as exemplifying experiential validity and offer this concept in lieu of "external generalizability" under the quantitative tradition.

\section{Description, Analysis, and Interpretation}

SR was a first semester junior in college at the time of the interview and although major psychological and emotional changes occur as a result of "going away to college", 
the interview was only about two years removed from when SR graduated from high school so the memories of caring and non-caring from his high school days were still relatively fresh. Probably more importantly, if we subscribe to the notion that "we may forget what people say but we will never forget how they made us feel" then remembrances that had an emotional impact on us (for good or ill) are still readily available to us even if these remembered instances were from our younger years. It is within this context that the responses from SR should be understood.

What follows are first the conversation prompts derived from the purpose of this study followed by description, analysis, and interpretation of the data that SR provided in response to these prompts. It should also be pointed out that while both SR and MR knew that the purpose of this group interview was to recall instances of caring and non-caring in school and to tease out impacts on motivation and learning, no specific examples were discussed in advance. Rather, the construct of caring was allowed to emerge as SR reflected upon these conversation prompts.

Prompt 1.1: Thinking about your days in elementary and high school, what instances of teacher caring or non-caring do you recall that had an effect on your motivation to do well in school?

Unfortunately, SR immediately related negative perceptions about his religion teacher in high school (SR attended a Catholic school). He said that during a typical 45 minute class, the teacher talked for 30 minutes about his own opinions and took no questions. SR also said that when a student got a question wrong on a test and asked about this question that the teacher's response was simply that "the answer was wrong and there was no more discussion or explanation." SR went on to say that this was probably the worst class that he ever had because it was simply "somebody standing up there telling students what he thought."

SR then related another instance of non-caring in high school when he described his English teacher from his junior (third) year. He said that whereas the religion teacher suffered from too much "self dialogue", his English teacher was almost the opposite. He described a typical class as one where students took turns reciting sections of literature by going up and down the rows. SR indicated that he felt like students were still being treated like they were in elementary school instead of individuals who were now capable of independent thinking. According to SR, this teacher sat at her desk, presumably listening to students read, while she did other work and then assigned homework for them to do at the end of the class.

As SR harkened back to elementary school, he recalled his fourth grade teacher as another example of non-caring similar to his examples from high school but he added that "at least we had a recess in elementary school whereas we did not in high school!" This elementary teacher was described not so much in terms of classroom practice but rather her demeanor and behavior in general. As noted above, SR indicated that unlike high school where he had to sit through long boring classes with no break, recess was a regular feature in elementary school. However, he said that when recess had to be held in the classroom because of bad weather, that the teacher would sit outside the door to the hallway and if any student's foot inadvertently would go beyond the threshold of the door that the student was immediately given a detention. SR indicated that "this type of 
teaching whether in elementary school, high school, or college results in students feeling like the teacher really does not care about them as individuals and so very little learning results."

In addition, SR referred to a "lack of respect" as being the major feeling he experienced during these times when caring was not demonstrated. It seems, based on these perceptions, that the personal characteristics of the teacher and the teacher's relationship to students were inextricably connected to student learning. Consequently, it may very well be that if teachers are not perceived as caring then their instructional methods may also be perceived as inadequate.

When encouraged to recall positive instances of caring in elementary school and high school, SR immediately said that "Mr. A" (a teacher in $8^{\text {th }}$ grade) is probably the most effective teacher I have had through my sophomore year of college." He described effectiveness in terms of the way that Mr. A interacted with him and his classmates and the respect that he showed towards their ideas and perspectives. SR described this interaction as one where Mr. A. did not place himself in a position of authority but rather where students felt like he listened to them as if "he was talking to another adult". SR said that consequently he and his classmates felt more "grown up" with this teacher and also felt like they mattered to him as individuals. He also identified "Mrs. D." who taught math in high school as a positive influence. SR confessed that he is not a "math person" but that Mrs. D. not only took the time to explain concepts to him that were unclear but did so on her own personal time such as before and after school or during lunch.

Prompt 1.2: To what extent do any of these instances of caring and non-caring continue to have an effect on you in terms of your motivation to do well in college?

Both of the instances of caring from high school described above regarding Mr. A. and Mrs. D. were not only deeply felt by SR but he said that they continue to have a positive impact on his learning in college. SR then abruptly posed this question "how can teachers in large lecture halls connect with their students?" and related this barrier to his negative elementary and high school experiences. The question about large lecture halls was actually the only connection to non-caring that the participant offered. He then went on to talk about three instances of caring that he has experienced as a college freshman and sophomore described next under Prompt 2. This was a welcome change from his predominant focus on instances of non-caring in elementary and high school.

Prompt 2: What instances of teacher caring or non-caring do you recall from your experiences thus far in college that have had a strong effect on your motivation to do well during the remainder of your college years and on your career aspirations?

The first instance described by the participant offered a great counterpoint to the negative experiences he described in high school. SR said that his college instructor for philosophy and theology, rather than lecture about his own thoughts and experiences like his high school teacher, so engaged him in the content "that it didn't matter how much time and work was needed -- I was motivated to learn because this teacher was very much interested in what he was teaching and also his students". SR went on to say that because of the obvious enthusiasm of the instructor and his concern for students that he 
was motivated to learn a subject that previously held little interest for him. During the interview he said that even though he was not Catholic (which was news to his parents) that he experienced valuable learning in this college class related to a deeper meaning of religion and that what he learned in grade school and high school was a sham. [both FR and MR tried to console themselves by classifying his response as a normal part of rebellion against all things parental]. He reiterated that while there was a lot of work required in this college class, he didn't care because he stressed that his college professor is the only religion teacher he ever liked because he cared and wanted them to learn.

The second instance of caring in college described by SR related to his Spanish teacher who required that assignments given every Monday, Wednesday, and Friday had to be submitted at the following class session. Regarding these assignments, he said that "while they were hard he gladly did them because he knew that the teacher really cared that he learned Spanish." He contrasted this positive experience with his negative high school English experience described earlier - "It was a lot different than doing mindless work at the end of the day in order to assign a grade."

He also cited high teacher expectations (for both his religion and Spanish teachers) as something that had a very positive effect on him although these expectations presented formidable challenges. However, he went on to say that the "personal care that these two teachers exhibited dwarfed the challenge of the work". He concluded his evaluation of these two teachers by saying that they were passionate about what they taught and passionate about their students. [At this point, FR engaged in some "private speech" about the "Three R's" (Relationships-Relevance-Rigor) as the necessary sequence for creating a "learning classroom" where students" engagement in learning is the primary focus (Cooper \& Garner, 2012)]. When asked about negative instances of caring in colleges his immediate response (again) was "lecture halls don't work" but he added that in college "you almost are treated as an adult" [this elicited a discrete smile from both MR and FR!].

SR then recalled a third instance of caring during college that did not involve a college instructor per se but rather the owner of a café named the "Spirited Goat" located near his college. SR identified this individual as a person who had a very positive impact on him because of the respect and caring he felt as well as the wisdom he shared. He went on to relate an experience he had where he had such a great conversation with the owner that he forgot to pay him and the owner also forgot to ask him to pay. SR related that he was so moved by the genuine caring shown by the owner "that I went out of my way to go back to the shop to pay what I owed". Although this instance was not "academic" in the sense of formal schooling, it reinforced the construct of caring and also demonstrates that valuable learning experiences should be recognized as extending "beyond the walls" of the school.

SR characterized all three of these individuals (religion, Spanish teacher, and café owner) by saying that "all three of them had a balance of relationships, professorship, and setting expectations and who took the time to form a relationship that formed the basis for my learning." SR also said that he wasn't sure where he picked up the following quote -- "they don't care what you know until they know that you care" but he said that it epitomized these three teachers. [FR knew that the quote was from Madeline Hunter that he must have shared earlier - kids really do listen sometimes!]. 
Prompt 3. Based on all of the examples you provided from Elementary, High School, and College, what would you suggest to teachers so that they could have a stronger positive effect on their students in terms of their wanting to do well in school and to pursue their career aspirations?

When asked this question SR immediately responded with "don't get comfortable". He then went on to say that his current experience working part time as a supervisor for a nutrition company taught him that he needs to "talk to the new person in the room" because everyone is learning something new including him and that both teachers and students should consider themselves as "perpetual students". He then said that teachers and professors should teach as if the labels of "teacher" and "student" are removed in order to create an environment where teachers are seen as fellow learners. He added that when he presents to a group of people that it's like he is "teaching and learning for the first time. When asked about the concept of caring, he connected it to the idea of us all being perpetual students "because teachers are human beings just like their students and that by learning right along with their students it comes across as genuine caring." The final research question applies to the Mother Researcher (MR) in terms of her reactions to the responses of SR.

Prompt 4. Based on what you have heard during this interview what reactions do you have?

While MR intentionally did not interject during the interview (except for saying that she really did not know how deeply negative experiences had affected SR), she now joined SR in discussing the ill effects of large lecture halls in college. She especially resonated with his feeling that he felt like he was treated like a number and that many students are lost both physically and mentally in such a large classroom environment. Because MR had experienced the same kind of environment in college, she commiserated with SR about this experience. In addition, because she owns her own company to educate adult students to use computer software, she was especially sensitive to the load on the teacher in such a large classroom since it prevents the teacher from developing any kind of relationship with students. She also agreed with SR that the workload for a teacher with such a large number of students would be quite overwhelming and again would prevent personal relationships and communication. This conversation between SR and MR ended the interview.

\section{Implications of Caring for Researcher and Teacher Preparation: FR's Reflections}

What is disturbing about SR's elementary and high school remembrances is not only the perceived lack of caring, but that these instances were foremost in the memory of SR rather than more positive experiences. It is also important to note the close connection between the teaching process and the impact on student perceptions of teachers caring about their students including their views and perspectives. In addition, what became most apparent during this interview was that SR automatically linked his interest and commitment to put forth effort in a subject matter, regardless of his prior interest, to the passion of teachers for their subject and the concern that they evidenced for their 
students. Hopefully someday positive remembrances will overshadow the negative instances in his mind.

I recognize that our more quantitatively-inclined colleagues would point out that there is too much "noise" or confounding of variables to be able to deem findings valid and therefore quite problematic for generalizing beyond this admittedly small sample size of $\mathrm{n}=1$. On the first count of noise and confounding of variables I plead "guilty" and happily so because I don't think that the complexity of human beings, including learning and teaching, is amenable to partitioning of variables. As for the second charge of findings not being valid, I also admit that, judged by the quantitative criteria of validity or even by the criteria of credibility put forward by some qualitative researchers, that the findings from this study would not be considered trustworthy especially since they are based on data obtained from just one primary participant. However, I appeal to readers to evaluate the findings of this study, not based on the traditional criteria of internal or external validity, but rather to draw upon their own life's experiences in order to come to their own conclusions about trustworthiness - we refer to this as experiential validity.

To carry this idea of experiential validity a bit further, I ask you to think back to those teachers who made a real difference in the way that you felt about a subject, yourself, or your future. Was it not those teachers who you perceived as caring about you as an individual who you still remember as having a positive impact on your life even if the particular way that it was expressed may have varied among these teachers? Whenever we find ourselves nodding in agreement as we think back to our own experiences throughout our lives, aren't we giving silent assent to the validity of what we hear now? In fact, whenever two or more individuals really agree on a perspective based on their own history and interpretation of this history, does this not constitute a type of validity because of a shared perceptual understanding of phenomena? And, while this shared understanding cannot be shown to be statistically generalizable, I venture to hypothesize that this generalizability could be confirmed through large-scale interviews.

So if our solitary participant does in fact speak for many of us then what might schools of education that prepare future teachers and those departments that prepare researchers take from these findings? I would suggest that caring, although not a variable that is typically used in prediction equations, is critically important in helping students to grow and achieve academically, emotionally, and socially. One of the things that I believe must happen is that education must shed the paradigm where scores on achievement tests, that are concerned primarily with right and wrong answers, serve as the primary indicators of student, teacher, or school success (Cooley \& Bernauer, 1991; Powell, Bernauer, \& Agnihorti, 2011). Rather, if we begin with the belief that every student has unique interests, motivations, capabilities, potential, and ability to learn, should we not first discover what motivates our students to learn and then adapt our teaching approaches based on this recognition?

If schools of education should include "soft" concepts such as caring in their preparation programs, what about programs that prepare students to conduct research in schools? While I was trained to become an educational researcher it was strictly in line with the quantitative paradigm where the search was on for "variables" that could be used to help "explain and predict" student cognitive achievement (as measured on tests) using techniques such as regression analysis and factor analysis. It is the ability to compartmentalize in order to arrive at cause-effect statements and then to generalize 
these statements that is at the heart of the quantitative paradigm. It seems that it would be both problematic and unwise to somehow transform the construct of caring into a variable that could be analyzed quantitatively. On the other hand, the qualitative paradigm can readily admit soft variables such as "caring" into its methodologies since it's ontology is not anchored in a stable reality that can be parceled into variables but rather is embedded in multiple perceptual realities.

A solution to this apparent problem may be for teacher preparation and educational research programs to not only talk about "mixed methods" but to also recognize that when it comes to the complexity of teaching and learning, that while quantitative methodologies can be used to investigate the impact of some aspects of the educational system (such as SES, expenditures, school size, etc.), that they are of limited usefulness when investigating the intimacy of teaching and learning. Rather, it is those very things that promote student motivation and interest in learning such as caring and high expectations that more than likely hold the real key to doing well academically. On the other hand, when it comes to assessing the impact of social and economic factors on schools, the sophisticated techniques employed by quantitative researchers admirably fit the bill. It is therefore suggested, based on the findings of this study and this researcher's own sense of "experiential validity", that educational research should start with the learner and then move outward to those influences that are more peripheral to teaching and learning. I am quite sure that there is a place for every type of educational inquiry as we search for ways to create a more caring and effective educational environment.

Looking to literature as another manifestation of experiential validity, Thomas Mann (1952) in his novel The Magic Mountain, speaks through his characters thus....

One day all the world would realize that our system, which had developed out of the cloister school of the Middle Ages, was a ridiculous bureaucracy and anachronism, that nobody in the world any longer owes his education to his schooling, and that a free and public instruction through lectures, exhibitions, cinematographs, and so forth was vastly to be preferred to any school course (p. 519).

Although dated both historically and geographically, I wonder how many of us might agree with this position when viewed through the lens of experiential validity; that is when we as adults look inward and backward to discover what really mattered in our cognitive, emotional, moral, and social growth is it not those teachers who demonstrated caring as well as those individuals who, while not a part of the formal school system such as the owner of the "Spirited Goat" café, who have had a lasting positive impact on us as learners?

Noddings (2005) writes persuasively that the primary purpose of education is not cognitive but rather moral and that caring and growth should be of primary concern rather than a focus on achievement. This thesis matches well to the purpose statement offered earlier. However, she "complicates" the issue of caring when she notes that even if teachers try to be caring that these efforts must be perceived as such in order to have a positive impact on students. In fact, it could very well be the case that some of the teachers that SR perceived as non-caring may have been well-intentioned. However, perceptions can become quite complex within the swirl of the school milieu where power differences intermix with the ever-changing chemistry of peer relations and "growth 
pains". Again, this suggests that the traditional way of conducting educational research is not well-suited for identifying and appreciating these complexities.

Heshusius (1996) begins her article by describing her experiences as a graduate student in special education with a somewhat humorous (but mostly sad) account of her first course in an American university. She was late for her "Learning Theories for Educators" course and thought that when she heard the professor talk about rats that she was in the wrong classroom. However, she discovered that she was indeed in the right classroom and then adds "needless to say, at the end of the course we were still talking about rats and pigeons doing very strange and silly things to get a pellet of food into their half-starved bodies" (p. 50). The fact that this anecdote revolves around behavioral learning theory is no coincidence since the tenets of behavioral theory with its focus on measurable performances fits perfectly with the quantitative paradigm. Again, it would appear to be a very difficult task to see how the attributes of caring in the classroom fits into this educational paradigm.

The question also arises how we would gain any important information by quantifying something that is important in its own right and which would lose its essence if we tried to quantify it. It seems that trying to do so would be similar to trying to quantify the characteristics of poetry, drama, or art. Because the experience that Heshusius (1996) described was to help prepare aspiring teachers to work with students with learning differences, makes it especially depressing since it treats these students not as individuals with unique emotional, social, and moral needs but only as students who need "fixed" so that they can function in the real world. And, if teachers go into classrooms steeped in this mindset, then the construct of caring must indeed "take a backseat" to the more quantifiable and measurable aspects of learning. We should not let this happen. 


\section{References}

Bauswell, R.B. (1994). Conducting meaningful experiments: 40 steps to becoming a scientist. Thousand Oaks, CA: Sage.

Bernauer, J. A., Lichtman, M., Jacobs, C., \& Robertson, S. (2013). Blending the old and the new: Qualitative data analysis as critical thinking and using Nvivo with a generic approach. The Qualitative Report, 18, 1-10. Retrieved from http://www.nova.edu/ssss/QR/QR18/bernauer2.pdf

Bernauer, J. A., Semich, G., Klentzin, J. C., \& Holdan, E. G. (2013). Themes of tension surrounding research methodologies education in an accelerated, cohort-based doctoral program. International Journal of Doctoral Studies, 8, 173-193. Retrieved from http://ijds.org/V olume8/IJDSv8p173-193Bernauer0397.pdf

Bernauer, J. A. (2015a). Opening the ears that science closed: Transforming qualitative data using oral coding. The Qualitative Report, 20(4), 406-415. Retrieved from http://www.nova.edu/ssss/QR/QR20/4/bernauer1.pdf

Bernauer, J. A. (2015b). Reflections on Catholic education in the USA: A dialogue across generations from the 1950s to the 2000s. International Studies in Catholic Education, 7(1), 74-93. doi: 10.1080/19422539.2014.998500

Cooley, W. W. \& Bernauer, J.A. (1991). School Comparisons in statewide testing programs. In R. Stake (Ed.), Advances in program evaluation (Volume 1, pp. 159-170). London: JAI Press Inc.

Cooper, N. \& Garner, B.K. (2012). Developing a learning classroom: Moving beyond management through relationships, relevance, and rigor. Thousand Oaks, CA: Corwin.

Fleming, V. (Producer), \& Cukor, G. (Director). (1939). Gone with the wind. United States: Selznick International Pictures.

Heshusius, L. (1996). Of life real and unreal. In Lous Heshusius and Keith Ballard (Eds.),From positivism to interpretivism and beyond (pp. 50-55). New York, NY. Teachers College Press.

Hunter, M. (1982). Mastery teaching. El Segundo, CA: TIP Publications.

Mann, T. (1981). The magic mountain. New York, NY: Alfred A. Knopf, Inc.

Moore, M.R. (2001). An American's journey to kindergarten's birthplace. Childhood Education 79 (1), 15-20.

Noddings, N. (2005). The challenge to care in schools: An alternative approach to education ( $2^{\text {nd }}$ ed.). New York, NY: Teachers College Press.

Pilcher, N. \& Cortazzi, M. (2016). Dialogues: QUANT research on QUAL methods. The Qualitative Report, 21(3), 450-473.

Polanyi, M. (1958). Personal knowledge. Chicago, IL: The University of Chicago Press.

Powell, J. C., Bernauer, J. A., \& Agnihorti, V. (2011). Chapter 18: Learning from incorrect answers on multiple-choice tests: Implications for a new teaching paradigm. In Isaias, P. et al., Towards learning and instruction in web 3.0 advances in cognition and educational psychology. (pp. 265-287). New York, NY: Springer. ISBN: 978-972-893927-4

McCartney, P. (1964). Can't buy me love. [ The Beatles] Paris, France: Capitol Records.

Wolcott, H.F. (1994). Transforming qualitative data: Description, analysis, interpretation. Thousand Oaks, CA: Sage. 